\title{
BIOCHEMICAL AND NUTRITIONAL COMPONENTS OF SELECTED HONEY SAMPLES
}

\author{
Lee Suan Chua ${ }^{\varpi}$, Nur Ardawati Adnan \\ Metabolites Profiling Laboratory, Institute of Bioproduct Development, Universiti Teknologi Malaysia \\ 81310 UTM Skudai, Johor Bahru, Johor, Malaysia
}

\begin{abstract}
Background. The purpose of this study was to investigate the relationship of biochemical (enzymes) and nutritional components in the selected honey samples from Malaysia. The relationship is important to estimate the quality of honey based on the concentration of these nutritious components. Such a study is limited for honey samples from tropical countries with heavy rainfall throughout the year.

Methodology. A number of six honey samples that commonly consumed by local people were collected for the study. Both the biochemical and nutritional components were analysed by using standard methods from Association of Official Analytical Chemists (AOAC). Individual monosaccharides, disaccharides and 17 amino acids in honey were determined by using liquid chromatographic method.

Results. The results showed that the peroxide activity was positively correlated with moisture content $(r=0.8264)$, but negatively correlated with carbohydrate content $(r=0.7755)$ in honey. The chromatographic sugar and free amino acid profiles showed that the honey samples could be clustered based on the type and maturity of honey. Proline explained for $64.9 \%$ of the total variance in principle component analysis (PCA). Conclusion. The correlation between honey components and honey quality has been established for the selected honey samples based on their biochemical and nutritional concentrations. PCA results revealed that the ratio of sucrose to maltose could be used to measure honey maturity, whereas proline was the marker compound used to distinguish honey either as floral or honeydew.
\end{abstract}

Key words: honey, sugar, amino acid, peroxide activity, diastase number

\section{INTRODUCTION}

Honey is a worldwide recognised natural food which has high nutritional value and many beneficial health promoting effects. It consists mainly of carbohydrates (at least $60 \%$ in mass ratio), particularly reducing sugars such as fructose and glucose as fast energy source upon consumption. The minor components in honey include amino acids, vitamins, organic acids, minerals and various phytochemicals [Kaskoniene et al. 2010]. Somehow, the biochemical composition of honeys varies greatly dependent on the floral, regional and climatic conditions. Because of the great variation, extensive research has been carried out to classify and identify the origin of honey in relation to its physical and biological properties. To our knowledge, the study on the relationship between the biochemical (enzymes) and nutritional components of honey is very limited. Often, the quality of honey is the major concern of honey consumers, regardless of honey origin. This relationship is very important for food processing industry, particularly for those industries using honey as ingredient in their food products. 
The biochemical components, namely enzymes are closely related to the nutritional content and honey freshness. Even though enzymes are present in minute amount, they have significant effect on the quality of honey. This is because enzymes would significantly affect the protein content, free amino acid profile and acidity of honey samples. Mostly, enzymes found in honey samples are secreted from bee salivary, namely oxidases, catalases and amylases [Gheldof et al. 2002]. These enzymes would break down complex sugars into simple sugars such as fructose and glucose. The simple sugars might also be further catalysed into alcohol and acetic acid under an appropriate amount of moisture content at the right temperature condition because of fermentation. Besides affecting the $\mathrm{pH}$ value, the activity of enzymes might change the flavour and aroma of honey after fermentation. Of the amino acids, proline has been reported as the most abundant amino acid in honey samples [Rebane and Herodes 2008]. It was proved from the analysis of sugar-fed honey that proline came from the salivary secretion of honey bees during nectar conversion [Iglesias et al. 2004].

Since enzymes are present in trace amount, many studies are likely to focus on sugar composition for the determination of honey origin [Da Costa Leite et al. 2000, Mateo and Bosch-Reig 1997, Weston and Brocklebank 1999]. Besides as macronutrient, the composition of monosaccharides and disaccharides, and their ratios could be used to determine the degree of honey maturity. Usually, ripen honey samples have lower disaccharides such as sucrose and maltose content than those from honey harvested at an earlier stage. This is because most of disaccharides have been converted into monosaccharides by the action of enzymes. Hence, the predominant sugars and their ratios are crucial parameters for honey characterisation.

In the present study, the biochemical and nutritional components of honey samples were investigated for better understanding of the relationship between both components. The chromatographic profiles of sugars and amino acids in the honey samples were also determined and clustered based on the statistical pattern recognition tool such as unsupervised multivariate analysis. The results of experimental data have statistically explained the strong relationship between biochemical and nutritional components.
The ratio of sucrose to maltose could be used to measure honey maturity, whereas proline was the marker compound used to distinguish honey between floral and honeydew.

\section{MATERIAL AND METHODS}

\section{Honey samples}

A number of six honey samples were collected from different locations in the West Coast of Peninsular Malaysia. They were tualang (T, Koompassia excels), gelam ( $\mathrm{G}$, Melaleuca cajuputi), acacia (A, Acacia mangium) and three types of forest honey samples (F-NS, F-M1 and F-M2). F-NS and F-M1 were harvested from the bee hives located at rubber tree (Hevea brasiliensis) and oil palm (Elaeis oleifera) plantation, respectively, whereas F-M2 was harvested from the bee hive located at the jungle area. Tualang and gelam honey belong to floral honey and the rest were honeydew honey. They were harvested between the months of April and May 2011 from their honey combs hanging on the tree branches. They were stored in amber glass bottles at $20^{\circ} \mathrm{C}$ before analysis.

\section{Proximate analysis}

Proximate analysis was carried out on the honey samples. The proximate content, namely protein, fat, dietary fiber, carbohydrate, water and ash were determined based on the official analysis methods from Association of Official Analytical Chemists (AOAC). All experiments were carried out in triplicate.

The protein content was determined by Kjeldahl method based on the total nitrogen content from the AOAC Official Method 991.20, 2005. The fat content was determined by using acid hydrolysis method based on the AOAC Official Method 14.019, 1984. The dietary fibers consisted of the total, soluble and insoluble fibers of honey samples were determined based on AOAC Official Method 991.43, 1991.

The moisture content was measured by placing $5 \mathrm{~g}$ honey samples in an oven set at $105^{\circ} \mathrm{C}$ for 18 hours, according to the AOAC Official Method 925.10, 2002. The same samples were further analysed for the ash content by calcinating them in a furnace (Carbolite CWF 1100 , Keison Products, England) at $550^{\circ} \mathrm{C}$ until constant weight, according to the AOAC Official method 923.03, 1998. 
Carbohydrate value was estimated from Equation 1 [Charrondiere et al. 2004]. The energy values for the honey samples were calculated by using constant energy factors, namely $38 \mathrm{~kJ} / \mathrm{g}(9 \mathrm{kcal} / \mathrm{g})$ for fat, and 17 $\mathrm{kJ} / \mathrm{g}(4 \mathrm{kcal} / \mathrm{g})$ for both protein and carbohydrate on a dry weight basis (Equation 2) [Charrondiere et al. 2004].

$$
\begin{gathered}
\text { Total carbohydrate }(\mathrm{g} / 100 \mathrm{~g})=100- \\
-(\text { water }+ \text { ash }+ \text { protein }+ \text { fat }+ \text { dietary fiber }) \\
\text { Energy }(\mathrm{kcal} / \mathrm{g})=9(\mathrm{fat})+4(\text { protein })+ \\
+4(\text { carbohydrate })
\end{gathered}
$$

\section{Glucose oxidase activity with peroxide test}

The activity of glucose oxidase in honey samples was screened for peroxide accumulation using Merckoquant test strip (no. 10011) from Merck, Germany as described by Kerkvliet [1996]. Results are expressed in milligram of hydrogen peroxide accumulation in a liter of sample solution for an hour at $20^{\circ} \mathrm{C}$

\section{Diastase activity with Phadebas method}

The diastase activity (DN) of honey samples was determined by using an insoluble blue dyed crosslinked type of starch as the substrate [Bogdanov 2009, Bogdanov et al. 1997]. The substrate was hydrolyzed by the enzyme to produce blue water-soluble fragments and detected photometrically at $620 \mathrm{~nm}$ under the stipulated reaction conditions. The absorbance of the solution is directly proportional to the diastatic activity of honey samples as presented in Equation 3. Results are the mean value of triplicate data that expressed in diastase units per gram of honey sample.

$$
\mathrm{DN}(\text { units } / \mathrm{g})=35.2 \times \mathrm{A}_{620}-0.46
$$

\section{Sugar analysis by HPLC-RI}

The major sugar content of honey samples such as fructose, glucose, sucrose ( $\alpha$-D-glucopyranosyl b-D-fructofuranoside) and maltose ( $\alpha$-D-glucopyranosyl (1-4) D-glucopyranose) were analysed by using a HPLC system coupled to a refractive index detector (Jasco, Easton, US). A XBridge ${ }^{\mathrm{TM}}$ amide column with the dimension of $3.5 \mu \mathrm{m}, 4.6 \times 150 \mathrm{~mm}$ was used for the separation. The column was kept at $25^{\circ} \mathrm{C}$ throughout the analysis. The mobile phase was $75 \%$ acetonitrile in deionized water with an isocratic flow rate of $2 \mathrm{ml} / \mathrm{min}$. Honey samples $(0.5 \mathrm{~g})$ were dissolved in deionized water and vortexed vigorously before filtered for injection. The injection volume was $20 \mu 1$. The standard sugar solutions which consisted of a mixture of fructose, glucose, sucrose and maltose were prepared at different concentrations ranging from 5 to $20 \mathrm{~g} / \mathrm{kg}$ for calibration curve construction.

\section{Amino acid analysis by HPLC-PDA}

The amino acid profile of honey samples was determined by using a reserved phase HPLC (Waters 600 , Massachusetts, USA) connected with a PDA detector (Waters 996, Massachusetts, USA). A mixture of sixteen amino acid hydrolysate Standard H (Waters AccQ.Tag) was used to build the calibration curve for each amino acid ranging from 20 to $100 \mathrm{pmol} / \mu \mathrm{l}$. A vacuum dried sample aliquot $(0.25 \mathrm{mg})$ was hydrolysed by hydrochloric acid $(5 \mathrm{ml}, 6 \mathrm{~N})$ by constant boiling at $110^{\circ} \mathrm{C}$. After hydrolysis, the solution was topped up to $100 \mathrm{ml}$. A $10 \mu \mathrm{l}$ of the sample solution was then derivatized by a reconstituted AccQ.Fluor Reagent $(90 \mu 1)$ in AccQ. Fluor Borate Buffer on a hot plate at $55^{\circ} \mathrm{C}$ for $10 \mathrm{~min}$. The amine derivatizing reagent (AccQ.Fluor Reagent), 6-aminoquinolyl-N-hydrozysuccinimidyl activated heterocyclic carbamate was used specifically for both primary and secondary amino acids analysis.

The column was Nova-Pak C18 $(3.9 \times 150 \mathrm{~mm}$, $4 \mu \mathrm{m})$ and maintained at $37^{\circ} \mathrm{C}$ during separation. The mobile phases consisted of acetate-phosphate aqueous buffer (A) and $60 \%$ acetonitrile (B). The gradient of the mobile phases as follow; $100-67 \% \mathrm{~A}$ in $33 \mathrm{~min} ; 67-0 \%$ in $1 \mathrm{~min} ; 100 \% \mathrm{~B}$ for 3 min and equilibrate the column in $100 \% \mathrm{~A}$ for $8 \mathrm{~min}$. The total run time was $45 \mathrm{~min}$ with a flow rate of $1 \mathrm{ml} / \mathrm{min}$. Sample injection volume was $10 \mu 1$.

\section{Statistical analysis}

All data were subjected to statistical and chemometrical analysis. Unsupervised multivariate analytical tools such as principle component analysis (MarkerView 1.1) and cluster analysis ( $\mathrm{R}$ version 2.11.1) have been used to classify honey samples based on their sugar and free amino acid compositions. 


\section{RESULTS AND DISCUSSION}

\section{Proximate analysis of honey samples}

Proximate analysis is usually carried out to determine the nutritional values of foods and food based products. The nutrient content is essential not only for health promotion, but also for metabolic energy. The results of proximate analysis for all honey samples are presented in Table 1 . The $\mathrm{pH}$ of honey samples was in the narrow range between 3.21 and 3.50 . The $\mathrm{pH}$ values were in accordance with the acceptable range from 3.0 to 4.3 for honey as reported by Bogdanov 1999 .

It was found that the honey samples would be prone to granulation because of high moisture content (>20\%) [Rodriguez et al. 2004]. Somehow, the moisture content of tualang, gelam and acacia honey were lower than the forest honey samples. The lower moisture percent has contributed to the higher carbohydrate values of tualang, gelam and acacia honey samples, since the other chemical compositions such as ash, protein, fat and dietary fiber of all honey samples were not significantly different (Equation 3). It is clear that carbohydrates in all honey samples belong to available carbohydrates because unavailable carbohydrates are considered as dietary fiber [Charrondiere et al. 2004]. Therefore, the energy values for tualang, gelam and acacia honey are relatively higher than the forest honey samples. The energy value is mainly attributed by the high sugar content of honey samples.
The protein value was calculated based on the total nitrogen content multiplied by the conversion factor of 6.25 [Charrondiere et al. 2004]. All honey samples were considered to be genuine because their total nitrogen contents were more than $50 \mathrm{mg}$ per $100 \mathrm{~g}$ of honey, which exceeded the limit of $30 \mathrm{mg}$ per $100 \mathrm{~g}$ of honey [Rodriguez et al. 2004].

\section{Enzyme activity of honey}

Honey contains various types of enzymes, mostly secreted from bee salivary. Glucose oxidases and diastases are two of the enzymes that commonly found in honey samples. They might be antioxidants that effectively contribute to the antimicrobial property of honey. The presence of the enzymes could indicate the geographical and botanical origin of honey, as well as could be an indicator for the freshness of honey [Alvarez-Suarez et al. 2010]. The activity of the enzymes could also be a measure of honey exposure to heat during processing and storage.

The presence of glucose oxidase could be predicted from peroxide test. The peroxide test estimated that only F-NS (5.73 mg/L/hour) and F-M2 $(1.65 \mathrm{mg} / \mathrm{L} /$ hour) exhibited the peroxide activity. The rest of the honey samples might contain oxidases lower than 0.5 $\mathrm{mg} / \mathrm{L} /$ hour which could not be detected by the Merckoquant test strip.

The diastase activity measured the combined activities of both $\alpha$-amylases and b-amylases which were

Table 1. Proximate analysis results of honey samples

\begin{tabular}{lcccccccc}
\hline \multirow{2}{*}{ Honey } & \multirow{2}{*}{$\mathrm{pH}$} & Moisture & Ash & Protein & Fat & Dietary fiber & Carbohydrate & $\begin{array}{c}\text { Energy } \\
\text { kcal/g }\end{array}$ \\
\cline { 3 - 9 } & & & \multicolumn{2}{c}{$\%$ w/w } & & \\
T & $3.30 \pm 0.02$ & $26.51 \pm 0.40$ & $0.19 \pm 0.02$ & $0.36 \pm 0.05$ & 0 & 0 & 72.94 & 2.932 \\
G & $3.38 \pm 0.01$ & $26.50 \pm 0.90$ & $0.23 \pm 0.02$ & $0.70 \pm 0.13$ & 0 & 0 & 72.57 & 2.931 \\
A & $3.21 \pm 0.03$ & $20.62 \pm 0.30$ & $0.20 \pm 0.03$ & $0.51 \pm 0.08$ & 0 & 0 & 78.67 & 3.167 \\
F-NS & $3.45 \pm 0.01$ & $37.31 \pm 0.96$ & $0.20 \pm 0.03$ & $0.60 \pm 0.07$ & 0 & 0 & 61.89 & 2.450 \\
F-M1 & $3.50 \pm 0.02$ & $30.00 \pm 0.45$ & $0.25 \pm 0.03$ & $0.43 \pm 0.13$ & 0 & 0 & 69.32 & 2.790 \\
F-M2 & $3.45 \pm 0.02$ & $31.71 \pm 0.16$ & $0.27 \pm 0.02$ & $1.02 \pm 0.05$ & 0 & 0 & 67.00 & 2.721
\end{tabular}

Mean \pm standard deviation of triplicate data. 
secreted from bee salivary [Vit and Pulcini 1996]. The results found that the diastase activities of all honey samples ranged from 0.04 to 1.48 , which was far lower than the minimum value of 8 set by Codex Alimentarius [2001]. A unit of diastase explains the enzyme activity of one gram of honey required to hydrolyze $0.01 \mathrm{~g}$ of starch in an hour at $40^{\circ} \mathrm{C}$ [Bogdanov 2009]. The diastase activity was varied and did not have significant trend in accordance with the type of honey samples. F-M2 has the highest diastase activity $(1.48 \mathrm{DN})$ and closely followed by tualang honey $(1.23 \mathrm{DN})$. The diastase activities for the rest of honey samples were less than $1 \mathrm{DN}$.

From the table of correlation matrix (Table 2), the peroxide activity was positively well correlated with moisture content (correlation coefficient, $r=$ $0.8264)$, but negatively correlated with carbohydrate $(r=-0.7755)$ and energy values $(r=-0.7747)$. The linear relationship between peroxide activity and moisture content indicated that oxidases require moisture for the expression of the enzyme activity. As discussed in previous subsection, the higher moisture content, the lower carbohydrate and energy values would be. This explains the negative correlation between peroxide activity and carbohydrate content.

\section{Chromatographic sugar composition of honey samples}

The chromatographic sugar analysis confirmed that the honey samples consisted mostly of monosaccharides such as fructose (35.79-44.91\%) and glucose (44.64-50.45\%), and followed by disaccharides such as sucrose $(0.02-6.09 \%)$ and maltose $(0.88-11.69 \%)$ as presented in Table 3.

The ratios of fructose to glucose $(\mathrm{F} / \mathrm{G})$ and sucrose to maltose $(\mathrm{S} / \mathrm{M})$ were in the range of $0.75-0.89$ and $0.01-17.14$, respectively. In contradiction with the previous study, the ratio of $\mathrm{F} / \mathrm{G}$ for all honey samples in this study was less than one [White 1978]. The result was not in good agreement with the previous finding that the $\mathrm{F} / \mathrm{G}$ ratio less than one would be adulterated honey [Auerbach and Bodlander 1976]. Interestingly, the $\mathrm{F} / \mathrm{G}$ ratio might be lowered by the peculiar metabolic activity of xerotolerant yeasts which could assimilate fructose through the process of fructophily [Tilbury 1980]. Supposedly, the actual proportion of fructose and glucose in any particular honey depends largely on the source of nectar collected by honey bees [Anklam 1998]. The honey samples used in this study were from the trusted suppliers and the forest honeys were harvested with witnesses. The difference in

Table 2. Correlation matrix of biochemical and nutritional components of honey samples

\begin{tabular}{|c|c|c|c|c|c|c|c|c|c|c|}
\hline & $\mathrm{pH}$ & Moisture & Ash & Protein & Fat & $\begin{array}{l}\text { Dietary } \\
\text { fiber }\end{array}$ & $\begin{array}{c}\text { Carbohy- } \\
\text { drate }\end{array}$ & Energy & Oxidases & Diastases \\
\hline $\mathrm{pH}$ & 1 & & & & & & & & & \\
\hline Moisture & 0.8166 & 1 & & & & & & & & \\
\hline Ash & 0.6562 & 0.2441 & 1 & & & & & & & \\
\hline Protein & 0.3362 & 0.3096 & 0.6803 & 1 & & & & & & \\
\hline Fat & na & na & na & na & 1 & & & & & \\
\hline Dietary fiber & na & na & na & na & na & 1 & & & & \\
\hline Carbohydrate & -0.8645 & -0.9829 & -0.3417 & -0.3041 & na & na & 1 & & & \\
\hline Energy & -0.8612 & -0.9819 & -0.3201 & -0.2702 & na & na & 0.9994 & 1 & & \\
\hline Oxidases & 0.4018 & 0.8264 & -0.1538 & 0.2451 & na & na & -0.7755 & -0.7747 & 1 & \\
\hline Diastases & -0.2229 & 0.1572 & -0.0920 & 0.4954 & na & na & -0.0773 & -0.0597 & 0.3014 & 1 \\
\hline
\end{tabular}

na - not available. 
Table 3. Major sugar compositions of honey samples

\begin{tabular}{lccccccc}
\hline \multicolumn{1}{c}{$\begin{array}{c}\text { Carbohydrate } \\
\%\end{array}$} & $\begin{array}{c}\text { Rt } \\
\text { min }\end{array}$ & Tualang & Gelam & Acacia & \multicolumn{3}{c}{ Forest } \\
\cline { 7 - 9 } Fructose & 4.65 & 41.732 & 44.908 & 39.046 & 38.582 & 35.786 & 42.145 \\
Glucose & 5.34 & 47.134 & 50.447 & 44.648 & 47.024 & 47.595 & 48.083 \\
Sucrose & 7.23 & 1.017 & 0.017 & 4.900 & 0.651 & 5.299 & 6.090 \\
Maltose & 8.80 & 4.491 & 1.291 & 0.875 & 2.035 & 9.598 & 11.693 \\
Fructose/Glucose & & 0.885 & 0.890 & 0.875 & 0.820 & 0.752 & 0.877 \\
Sucrose/Maltose & & 0.226 & 0.013 & 17.137 & 0.320 & 0.552 & 0.521 \\
Glucose/Water & & 1.574 & 1.695 & 1.894 & 1.034 & 1.193 & 1.329 \\
\hline
\end{tabular}

the concentration of fructose and glucose of all honey samples was ranging from 5.40 to $11.81 \%(\mathrm{w} / \mathrm{w})$. Honey crystallization could be accelerated when the glucose concentration is significantly higher than fructose as glucose is less water soluble [Rodriguez et al. 2004].

The value of $\mathrm{F} / \mathrm{G}$ ratio could be used as a favour indicator because fructose is much sweeter than sucrose and glucose [Kamal and Klein 2011]. Hence, gelam honey is the sweetest honey sample, followed by tualang, forest M2, acacia, forest NS and forest M1. The sweetness of the honey samples from Malaysia is lower than honey from the other countries such as Venezuela and Algeria which have higher fructose concentration. Blossom honey such as tualang and gelam honey samples contained higher fructose concentration than honeydew honey, namely forest honey samples. Therefore, this ratio was relatively higher for blossom honey samples used in this study. The total invert sugars were more than $83 \%$ for the honey samples. The glucose to water $(\mathrm{G} / \mathrm{W})$ ratio ranged from 1.03 to 1.89 .

The ratio of S/M indicates that maltose has higher concentration than sucrose, except for acacia honey. This acacia honey was harvested from the bee farm before ripening for experimental purpose. The high sucrose content of acacia honey proved the incomplete conversion of sucrose into glucose and fructose by worker bees. Sucrose was digested by several enzymes secreted from the hypopharyngeal glands of worker bees to break down the glycosidic bonds into simple sugars [Crane 1979] with about 95\% conversion [Guler et al. 2007]. Somehow, sucrose could be converted spontaneously during storage because of the presence of invertases in the honey samples. Sucrose is one of the important sugars that governed by The Council of the European Union [Council... 2002] to monitor the honey quality and adulteration. The legal limit for sucrose should be less than $5 \%$ on mass basis as stated in the Codex Alimentarius Commission [2001]. Honey that adulterated with high fructose syrup is usually high in sucrose level. Sucrose is believed to be detrimental to human health, particularly the deteriorative effects associated with aging [Chepulis et al. 2009]. Therefore, the sugar composition of honeys is largely dependent not only on the harvesting time, but also the climate and nectar source [Anklam 1998].

PCA on the composition of the predominant manosaccharides (fructose and glucose) and disaccharides (maltose and sucrose) showed that the honey samples could be distinguished into two significant clusters, namely orchard and wild type honey samples in the first principle component (PC1) (Fig. $1 \mathrm{a}$ and b). From the personal conversation with local professional bee hive hunters, it is known that honey is usually harvested from the matured bee hives approximately after the third week of bee hive construction. They could estimate the maturity of honey based on the shape of bee hives. According to the information given combined with experimental data, PCA on major sugar compositions could further cluster the honey samples according to the maturity of honey. It was found that acacia honey was the earliest harvest honey (a week), 


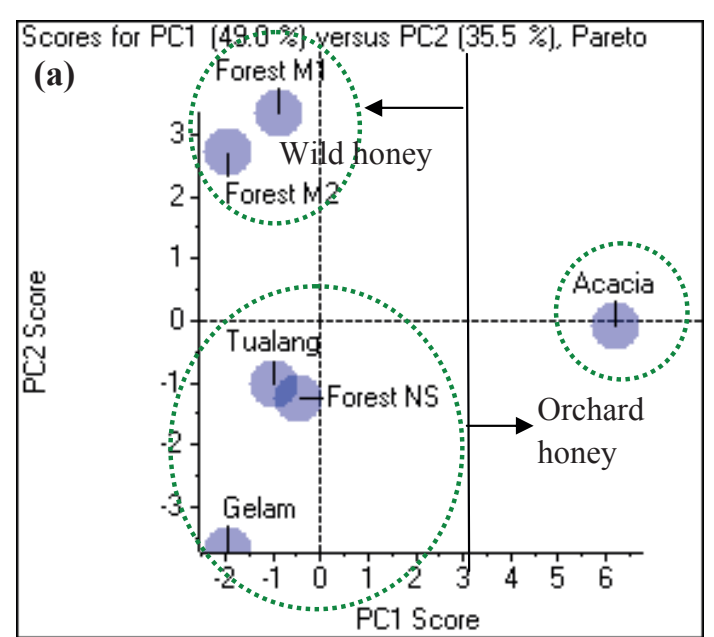

(c)

Type of honeys

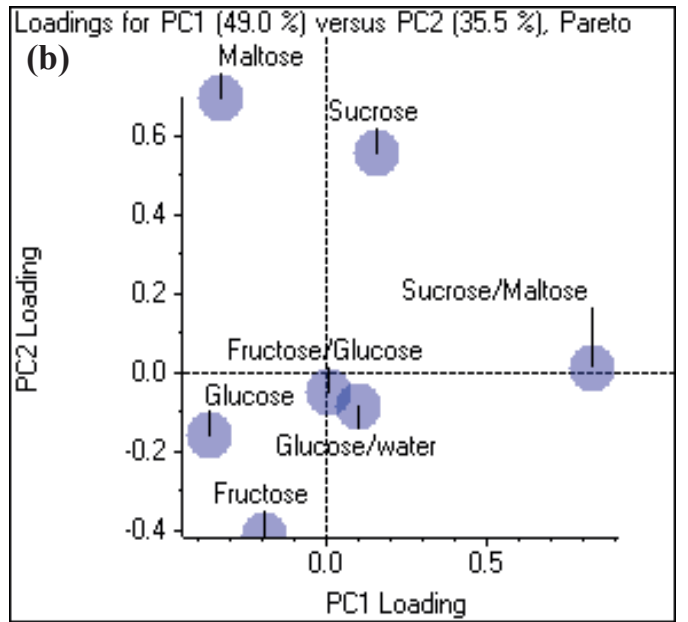

(d)

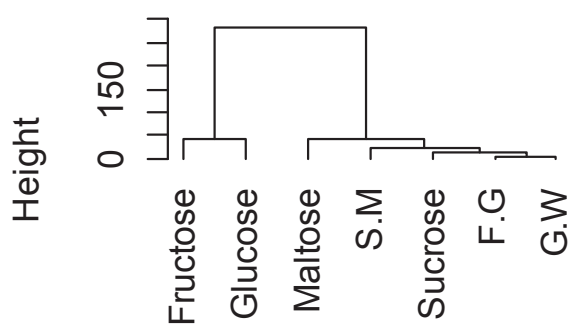

Saccharides and their ratios

Fig. 1. Score (a) and loading (b) plots of sugar composition and their ratios for honey samples. Their dendrograms based on the type of honeys (c) and sugar composition (d)

followed by forest M1 and M2 honey samples (about two weeks) and lastly the ripen honey samples were tualang, gelam and forest NS (about 3 weeks). In line with the PCA results, the dendrogram of cluster analysis grouped the honey samples into 3 major classes based on the maturity of honey (Fig. $1 \mathrm{c}$ ). While, the dendrogram based on the sugar content of honey samples could be grouped into two significant groups, namely monosaccharides (fructose and glucose), and disaccharides and their ratios (Fig. 1 d). Sucrose was the sugar marker of honey immaturity with the eigenvalue of 0.158 in the $\mathrm{PC} 1$. The immaturity of honey samples could also be indicated by the high concentration of maltose with the eigenvalue of 0.695 in the second principle component (PC2). Therefore, both major disaccharides gave the highest positive score for the $\mathrm{S} / \mathrm{M}$ ratio in $\mathrm{PC} 1$.

\section{Amino acid composition of honey samples}

There were sixteen types of amino acids had been hydrolysed and analysed by using AccQ.Tag method (Table 4). The results showed that acacia honey had 
Chua L.S., Adnan N.A., 2014. Biochemical and nutritional components of selected honey samples. Acta Sci. Pol., Technol. Aliment. 13(2), 169-179.

Table 4. Free amino acids in honey samples

\begin{tabular}{|c|c|c|c|c|c|c|c|c|c|}
\hline \multirow{2}{*}{ Amino acid } & \multirow{2}{*}{$\begin{array}{l}\text { Rt } \\
\text { min }\end{array}$} & \multirow{2}{*}{$\begin{array}{l}\text { LOD } \\
\mu \mathrm{g} / \mathrm{g}\end{array}$} & \multirow{2}{*}{$\begin{array}{l}\text { LOQ } \\
\mu \mathrm{g} / \mathrm{g}\end{array}$} & \multirow{2}{*}{$\begin{array}{c}\text { Tualang } \\
\mu \mathrm{g} / \mathrm{g}\end{array}$} & \multirow{2}{*}{$\begin{array}{c}\text { Gelam } \\
\mu \mathrm{g} / \mathrm{g}\end{array}$} & \multirow{2}{*}{$\begin{array}{l}\text { Acacia } \\
\mu \mathrm{g} / \mathrm{g}\end{array}$} & \multicolumn{3}{|c|}{ Forest, $\mu \mathrm{g} / \mathrm{g}$} \\
\hline & & & & & & & NS & M1 & M2 \\
\hline Asp & 16.69 & 2.678 & 8.115 & 0.001 & 0.000 & na & na & na & na \\
\hline Ser & 18.29 & 2.313 & 7.008 & 0.489 & 0.393 & na & na & na & na \\
\hline Glu & 19.62 & 3.212 & 9.733 & 0.162 & na & 0.145 & 0.064 & na & na \\
\hline Gly & 20.28 & 1.435 & 4.349 & 0.016 & 2.276 & na & na & na & na \\
\hline His & 20.76 & 2.881 & 8.731 & na & na & 4.109 & 4.346 & 0.088 & na \\
\hline Arg & 24.44 & 3.517 & 10.657 & na & 0.266 & na & na & na & na \\
\hline Thr & 24.82 & 2.339 & 7.086 & 0.871 & 6.406 & 0.743 & na & 2.275 & 1.478 \\
\hline Ala & 25.35 & 1.935 & 5.864 & 0.209 & 0.131 & na & 0.206 & na & na \\
\hline Pro & 26.55 & 3.629 & 10.998 & 0.008 & 0.002 & 16.351 & na & 12.231 & 14.926 \\
\hline Cys & 29.29 & 1.177 & 3.566 & na & na & 0.044 & na & 0.137 & 0.109 \\
\hline Tyr & 29.86 & 3.669 & 11.119 & 0.156 & 0.238 & 0.146 & 0.121 & na & na \\
\hline Val & 30.64 & 2.165 & 6.561 & 0.157 & 0.193 & na & na & na & na \\
\hline Met & 31.54 & 2.702 & 8.189 & 1.151 & 2.576 & 0.253 & 0.274 & 0.114 & na \\
\hline Lys & 33.20 & 2.961 & 8.972 & 0.070 & 0.176 & na & 0.153 & na & na \\
\hline Iso & 34.52 & 2.562 & 7.764 & 1.540 & 3.094 & 0.273 & 0.690 & na & 0.047 \\
\hline Leu & 35.15 & 2.697 & 8.171 & 0.222 & 0.142 & 1.214 & na & na & na \\
\hline Phe & 36.65 & 124.753 & 378.502 & na & na & na & na & na & na \\
\hline $\begin{array}{l}\text { Total amino } \\
\text { acid }\end{array}$ & & & & 5.051 & 15.894 & 23.279 & 5.855 & 14.845 & 16.558 \\
\hline
\end{tabular}

Rt - Retention time.

LOD - Limit of detection (3.3 standard deviation / slope of calibration curve).

LOQ - Limit of quantitation (10 standard deviation / slope of calibration curve).

na - not available.

the highest total amino acid content, followed by forest M2, gelam and forest M1. The total amino acid content was mainly contributed by proline, particularly for the honey samples of acacia, forest M1 and M2 which accounted for more than $70 \%$ in mass. In line with Baroni et al. [2009], high values of proline are typical for honeydew honey. However, proline was not detected in forest NS and only a small amount of proline found in tualang and gelam honey samples. It is also interesting to note that phenylalanine was not detected in all honey samples. The chromatograms for amino acids analysis in all honey samples are presented in Figure 2.
PCA had permitted a reduction of sixteen variables to four principle components for free amino acids in the honey samples. Based on the pareto scaling in PCA, it is clear that the presence of proline clustered the honey samples into two major classes. Acacia, forest M1 and M2 belong to the same class (honeydew honey) with higher similarity in amino acid profile. Proline is likely to be the amino acid marker to differentiate them from the other class consisting of tualang, gelam and forest NS. The absence of proline in the forest NS clustered it to the floral honey, even though forest honey is known as a mixture of several honeydews [Bertoncelj et al. 2011]. 
(a) Tualang

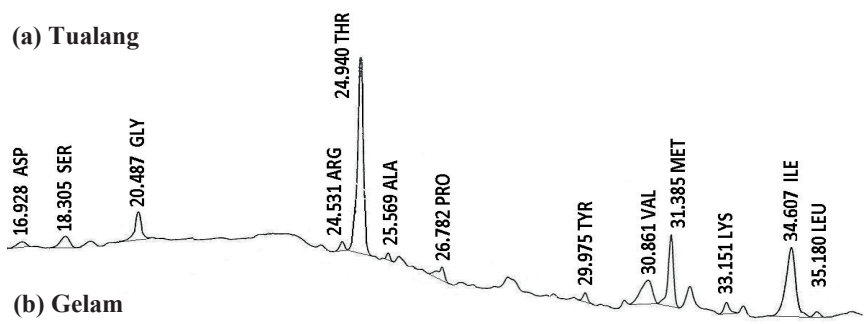

Gelam

(d) Forest NS

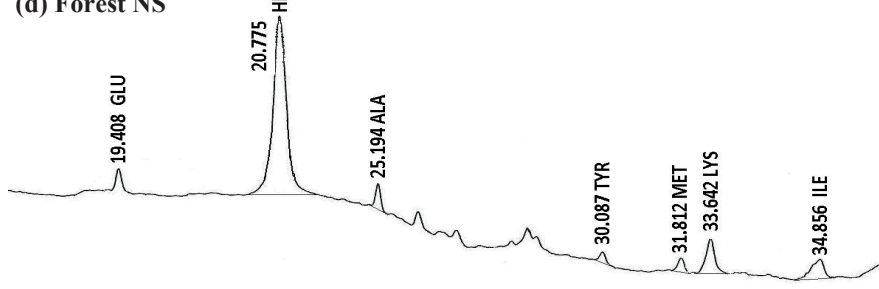

(e) Forest M1
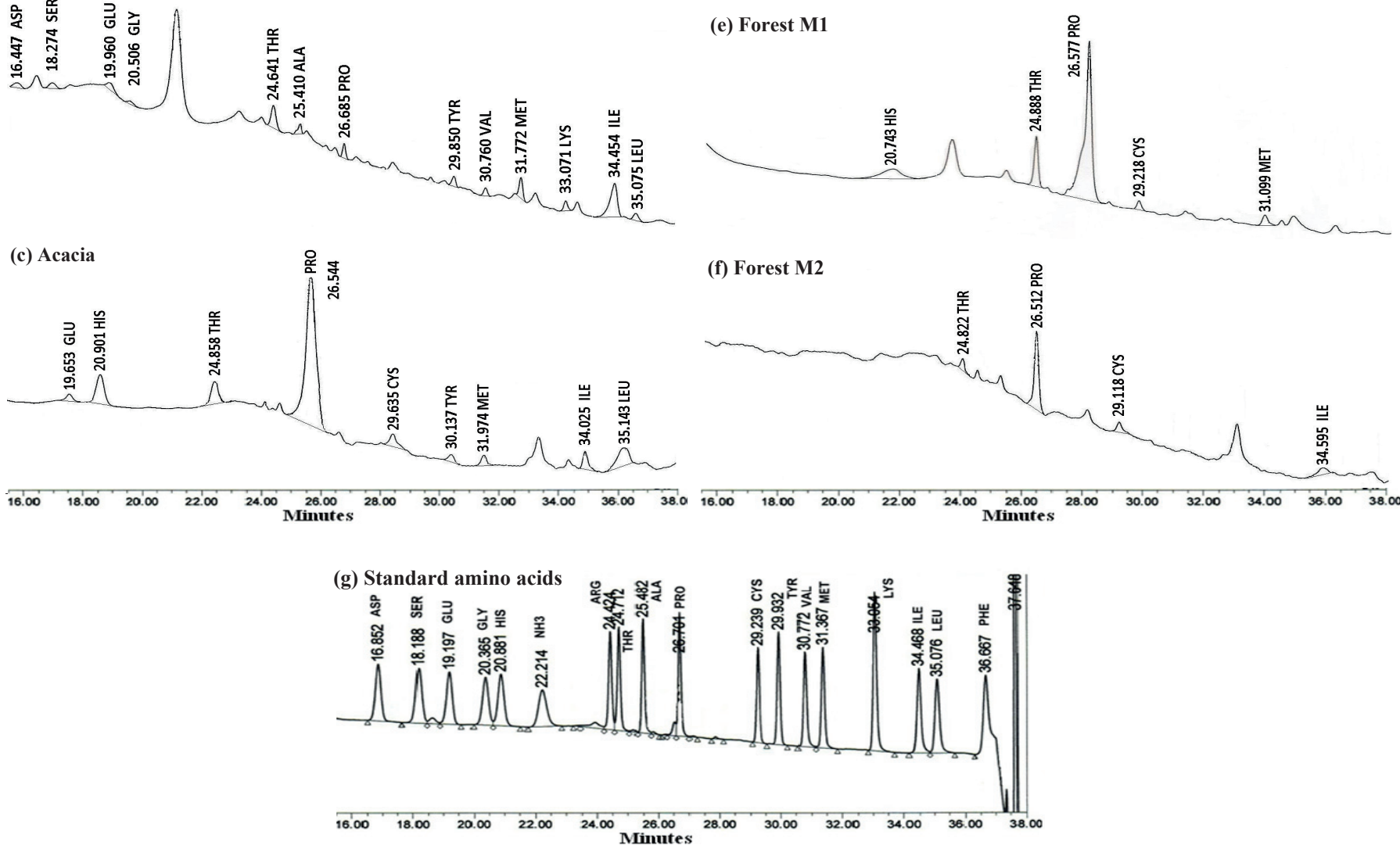

Fig. 2. Chromatograms of free amino acids for all honey samples compared to standard amino acids at $100 \mathrm{pmol} / \mu 1$

The first principle component explained for $64.9 \%$ of the total variance, mainly contributed by proline. The second and third principle components that accounted for $23.7 \%$ and $8.5 \%$ of the total variance were mainly contributed by threonine and histidine, respectively. The cumulative variance for four principle components is $99.8 \%$ which is larger than Spanish honey samples (78.25\%) [Nozal et al. 2004] and Estonia honey samples (81.5\%) [Rebane and Herodes 2008].

\section{CONCLUSION}

A number of six honey samples were collected from Malaysia and analysed for their biochemical and nutritional components. The honey samples were selected for this study because tualang, gelam and acacia honey are widely consumed by local people, whereas forest honey is mostly applied by those staying in the rural area. The results found that the honey samples exhibited a significant variation in the moisture, protein and 
carbohydrate content from proximate analysis. Both PCA and cluster analysis on the predominant sugar compositions showed that the honey samples could be grouped according to the maturity of honey. The maturity of honey samples could also be clustered based on the chromatographic free amino acid composition. Proline was the main amino acid marker (PC1) that contributed to the honey classification besides threonine (PC2) and histidine (PC3). Peroxide activity was only detected in the honey samples of forest NS and M2. The peroxide activity has strong positive correlation with moisture content, but strong negative correlation with carbohydrate and energy value of honey samples. This explains the expression of peroxide activity is closely depended on the moisture content, while the moisture content will indirectly affect the carbohydrate and energy value based on proximate analysis. It is also suggested to collect more honey samples for each type of honey at different seasons in order to draw more convincing conclusion.

\section{REFERENCES}

Alvarez-Suarez J.M., Tulipani S., Díaz D., Estevez Y., Romandini S., Giampieri F., Damiani E., Astolfi P., Bompadre S., Battino M., 2010. Antioxidant and antimicrobial capacity of several monofloral Cuban honeys and their correlation with color, polyphenol content and other chemical compounds. Food Chem. Toxicol. 48 (8-9), 2490-2499.

Anklam E., 1998. A review of the analytical methods to determine the geographical and botanical origin of honey. Food Chem. 63 (4), 549-562.

Auerbach F., Bodlander E., 1976. Distinguishing between true and artificial honey. In: The chemical analysis of foods. Ed. D. Pearson. Churchill Livingstone London.

Baroni M.V., Arrua C., Nores M.L., Faye P., Diaz del M.P., Chiabrando G.A., Wunderlin D.A., 2009. Composition of honey from Cordoba (Argentina): Assessment of North/South provenance by chemometrics. Food Chem. 114 (2), 727-733.

Bertoncelj J., Polak T., Kropf U., Korosec M., Golob T., 2011. LC-DAD-ESI/MS analysis of flavonoids and abscisic acid with chemometric approach for the classification of Slovenian honey. Food Chem. 127 (1), 296-302.

Bogdanov S., Martin P., Lullmann C., 1997. Harmonised methods of the European Honey Commission. Apidologie $28,1-59$.
Bogdanov S., 1999. Honey quality and international regulatory standards: Review by the International Honey Commission. Bee World 80 (2), 61-69.

Bogdanov S., 2009. Harmonised methods of the International Honey Commission. [online], http://www.bee-hexagon.net/en/network.htm [access" 22 December 2011].

Charrondiere U.R., Chevassus-Agnes S., Marroni S., Burlingame B., 2004. Impact of different macronutrient definitions and energy conversion factors on energy supply estimations. J. Food Compos. Anal. 17 (3-4), 339-360.

Chepulis L.M., Starkey N.R., Waas J.R., Molan P.C., 2009. The effects of long-term honey, sucrose or sugar-free diets on memory and anxiety in rats. Physiol. Behav. 97 (3-4), 359-368.

Codex Alimentarius Commission Standards, 2001. CODEX STAN 12-1981. Rev. 1 (1987), Rev. 2.

Council of European Union, Council Directive 2001/110/ EC of 20 December 2001 relating to honey. 2002. Off. J. Eur. Comm. L 10, 47-52.

Crane E., 1979. Honey: A comprehensive survey. International Bee Research Association (IBRA), Heinemann, London.

Da Costa Leite J.M., Trugo L.C., Costa L.S.M., Quinteiro L.M.C., Barth O.M., Dutra V.M.L., De Maria C.A.B., 2000. Determination of oligosaccharides in Brazilian honeys of different botanical origin. Food Chem. 70 (1), 93-98.

Gheldof N., Wang X.H., Engeseth N.J., 2002. Identification and quantification of antioxidant components of honeys from various floral sources. J. Agric. Food Chem. 50 (21), 5870-5877.

Guler A., Bakan A., Nisbet C., Yavuz O., 2007. Determination of important biochemical properties of honey to discriminate pure and adulterated honey with sucrose (Saccharum officinarum L.) syrup. Food Chem. 105 (3), 1119-1125.

Iglesias M.T., Lorenzo C.D., Polo M.D.C., Martin-Alvarez P.J., Pueyo E., 2004. Usefulness of amino acid composition to discriminate between honeydew and floral honeys. Application to honeys from a small geographic area. J. Agric. Food Chem. 52 (1), 84-89.

Kamal M.A., Klein P., 2011. Determination of sugars in honey by liquid chromatography. Saudi J. Biol. Sci. 18 (1), 17-21.

Kaskoniene V., Venskutonis P.R., Ceksteryte V., 2010. Carbohydrate composition and electrical conductivity of different origin honeys from Lithuania. LWT-Food Sci. Technol. 43 (5), 801-807. 
Chua L.S., Adnan N.A., 2014. Biochemical and nutritional components of selected honey samples. Acta Sci. Pol., Technol. Aliment. 13(2), 169-179.

Kerkvliet E., 1996. Screening method for the determination of peroxide accumulation in honey and relation with HMF content. J. Apicul. Res. 35 (3-4), 110-117.

Mateo R., Bosch-Reig F., 1997. Sugar profiles of Spanish unifloral honeys. Food Chem. 60 (1), 33-41.

Nozal M.J., Bernal J.L., Toribio M.L., Diego J.C., Ruiz A., 2004. Rapid and sensitive method for determining free amino acid in honey by gas chromatography with flame ionization or mass spectrometric detection. J. Chrom. A, 1047 (1), 137-146.

Rebane R., Herodes K., 2008. Evaluation of the botanical origin of Estonian uni- and polyfloral honeys by amino acid content. J. Agric. Food Chem. 56 (22), 10716-10720.

Received - Przyjęto: 4.10.2013

For citation - Do cytowania

Chua L.S., Adnan N.A., 2014. Biochemical and nutritional components of selected honey samples. Acta Sci. Pol., Technol. Aliment. 13(2), 169-179.
Rodriguez G.O. de., Ferrer B.S. de., Ferrer A., Rodriguez B., 2004. Characterization of honey produced in Venezuela. Food Chem. 84 (4), 499-502.

Tilbury R.H., 1980. Xerotolerant (osmophilic) yeasts. In: Biology and activities of yeasts. Eds F.A. Skinner, S.M. Passmore, R.R. Davenport. Academic Press London, 153-179.

Vit P., Pulcini P., 1996. Diastase and invertase activities in Meliponini and Trigonini honeys from Venezuala. J. Apicul. Res. 35 (2), 57-62.

Weston R.J., Brocklebank L.K., 1999. The oligosaccharide composition of some New Zealand honeys. Food Chem. 64 (1), 33-37.

White J.W. Jr, 1978. Honey. Adv. Food Res. 24, 287-374.

Accepted for print - Zaakceptowano do druku: 24.01.2013 